\title{
A Reliable and Quick Radial Thin Layer Chromatographic Method for the Diagnosis of Mono- and Disaccharide Disorders
}

\author{
By D. Biou
}

Department of Biochemistry (Pr. Agneray), Faculty of Pharmaceutical Sciences, Paris XI University, Chatenay-Malabry, France

\section{G. Dutot}

Department of Clinical Biochemistry, Centre Hospitalier, Versailles, France and

M. Pays

Department of Analytical Chemistry, Faculty of Pharmaceutical Sciences, Caen, France

(Received July 30, 1982/January 10, 1983)

Summary: The authors propose a radial thin layer chromatographic method for the separation of mono- and disaccharides, which shows better resolution, and is more sensitive $(0.25 \mu \mathrm{g}$ for glucose) and less time-consuming $(20 \mathrm{~min})$ than the linear technique. Moreover, the procedures used for the detection of sugars and their dansyl-derivatives (staining with naphthoresorcinol and fluorescence of the dansyl-hydrazones) make the identification more specific and reliable. This simple method is quite suitable for the analysis of biological samples (urine, faeces) and the diagnosis of metabolic disorders in children.

Eine zuverlässige und schnelle radiale dünnschichtchromatographische Methode zur Diagnose von Mono- und Disaccharid-Stoffwechselstörungen

Zusammenfassung: Die hier vorgeschlagene radiale dünnschichtchromatographische Methode zur Trennung von Mono- und Disacchariden zeigt eine bessere Auflösung, ist empfindlicher ( $0,25 \mu \mathrm{g}$ Glucose) und weniger zeitraubend (20 min) als das lineare Verfahren. Darüberhinaus machen die Verfahren für den Nachweis der Zucker und ihrer Dansylderivate (Färbung mit Naphthoresorcin und Fluoreszenz der Dansylhydrazone die Identifizierung spezifischer und zuverlässiger. Die Methode ist gut geeignet für die Analyse biologischer Proben (Harn, Faeces) und die Diagnose von Stoffwechselstörungen bei Kindern.

\section{Introduction}

The investigation and identification of sugars in urine or faeces can reveal or confirm a carbohydrate intolerance. The sugars concerned are mono- and disaccharides: xylose, fructose, glucose, galactose, lactose, sucrose, maltose. Affecting children in particular, these disorders result from either a malabsorption or an enzyme deficiency.
The linear thin layer chromatographic procedures commonly used for the screening of these metabolic diseases are time-consuming (1) and have poor resolution.

To improve performance, we propose a powerful separation technique involving radial diffusion. It was previously used by Mac Laren \& Won (2) for the detection of more complex oligosaccharides. This 
method allows a complete separation of mono- and disaccharides within twenty minutes. Prior to chromatography, carbohydrates are condensed with dansylhydrazine to yield fluorescent compounds (3). Sugars that do not react with dansyl hydrazine can be visualised by spraying with a colorimetric reagent. Furthermore, the different mobilities of derivatized and underivatized sugars make this technique very specific.

\section{Materials and Methods}

\section{Materials}

For radial chromatography, we used the Selecta Sol System (4), W2 wicks and precoated TLC plates $10 \times 10 \mathrm{~cm}$ (silica gel F $1500 \mathrm{LS}$ 254), all provided by Schleicher and Schüll (Dassel, FRG).

Dansyl hydrazine (1-dimethylamino-naphthalene 5-sulphonyl hydrazine) was supplied by Pierce Chemical Company (Rockford, Ill. USA). The other chemicals were obtained from Merck (Darmstadt, FRG).

Microsyringe Hamilton No. $7101 \mathrm{~N}$.

UV lamp $350 \mathrm{~nm}$ Camag TL $900 \mathrm{U}$.

\section{Methods}

\section{Sample preparation}

Urines: these must be collected with a preservative agent and stored at $-20^{\circ} \mathrm{C} .1 \mathrm{ml}$ of 24 hour urine is deionized by shaking for ten minutes with an equal volume of mixed resin AG-501-X8 (D), then centrifuged for 5 minutes at $3000 \mathrm{~min}^{-1}$.

Faeces: sugars are extracted from $0.5 \mathrm{~g}$ of 24 hour faeces with 1 $\mathrm{ml}$ of $0.15 \mathrm{~mol} / \mathrm{l} \mathrm{NaCl}$; after centrifugation, the supernatant is treated as described above.

\section{Fluorescent labelling of the sugar reducing function}

We have modified the experimental conditions previously described by Avigad (3). Add $100 \mu \mathrm{l}$ of a $40 \mathrm{~g} / \mathrm{l}$ solution of trichloroacetic acid and $200 \mu \mathrm{l}$ of a $2 \mathrm{~g} / \mathrm{l}$ dansylhydrazine solution in acetonitrile to a $100 \mu \mathrm{l}$ sample containing 0.5 to $25 \mu \mathrm{mol}$ of reducing sugars. Heat the mixture for ten iminutes at $80^{\circ} \mathrm{C}$, then cool to room temperature. The dansylated solution can be stored for up to one week at $-20^{\circ} \mathrm{C}$ in darkness.

\section{Chromatography}

Apply samples with a $1 \mu$ microsyringe. When using the radial technique, deposit eight spots around the perimeter of a $2 \mathrm{~cm}$ diameter circle, the centre being a W-2 diffusion wick. For each spot, the template defines a triangular diffusion area in a similar way to the "V" bands method of Prey et al. (5). As standard' sugars, use $50 \mathrm{~g} / \mathrm{l}$ solutions of ribose, xylose, fructose, glucose, galactose, sucrose, lactose and maltose, which are the most commonly encountered in pathology. On the plate are spotted $0.025 \mu \mathrm{l}$ of non dansylated and $0.1 \mu \mathrm{l}$ of dansylated sugars.

Test material is applied to the chromatogram at the rate of $1.25 \mu \mathrm{l}$ (non dansylated) and $5 \mu \mathrm{l}$ (dansylated) for every gram of reducing sugar per liter. Two migrations are successively rự in the following solvent system: ethyl acetate/isopropänol/wạter (solvents I and II, table I). The method requires only $2 \mathrm{ml}$ of each mobile phase.

\section{Detection}

Two procedures are used

1) Fluorescence: after the first development in solvent $I$, observe at $350 \mathrm{~nm}$ the characteristic bright yellow fluorescence of the dansylhydrażones.

2) Colorimetry with naphthoresorcinol reagent: Add $1 \mathrm{ml}$ of concentrated sulphuric acid to $25 \mathrm{ml}$ of freshly prepared $1 ; 3$-dihydroxynaphthalene $(2 \mathrm{~g} / 1$ solution in pure ethanol).

Spray this reagent on the dried plate after the second development in solvent II. The colored spots corresponding to the free sugars can be visualised after heating at $110^{\circ} \mathrm{C}$ for five minutes.

Tab. 1. Comparative study of the resolution of free sugars and their dansylhydrazones by linear and radial thin layer chromatography.

\begin{tabular}{|c|c|c|c|c|c|c|c|c|c|}
\hline \multirow[t]{4}{*}{ Sugar } & \multicolumn{4}{|c|}{ Solvent I** } & \multicolumn{5}{|c|}{ Solvent III*** } \\
\hline & \multicolumn{4}{|c|}{ Migration } & \multicolumn{4}{|c|}{ Migration } & \multirow[t]{3}{*}{ Colour } \\
\hline & \multicolumn{2}{|c|}{ Linear } & \multicolumn{2}{|c|}{ Circular } & \multicolumn{2}{|c|}{ Linear } & \multicolumn{2}{|c|}{ Circular } & \\
\hline & $R_{f_{1}}$ & $\mathbf{R}_{\mathbf{x}_{1}}{ }^{*}$ & $\mathbf{R}_{\mathrm{f}_{\mathrm{f}}}$ & $\mathrm{R}_{\mathrm{x}_{1}}^{*}{ }^{*}$ & $\mathbf{R}_{\mathrm{f}_{2}}$ & $\mathrm{R}_{\mathbf{x}_{\mathbf{2}}}{ }^{\prime}$ & $\mathbf{R}_{\mathfrak{f}_{\mathbf{2}}}$ & $\mathbf{R}_{\mathbf{x}_{2}}{ }^{*}$ & \\
\hline Ribose & 0.70 & 132 & 0.82 & 119 & 0.41 & 205 & $0 . \overline{71}$ & 158 & blue \\
\hline Xylose & 0.67 & 126 . & 0.79 & 114 & 0.35 & 175 & 0.63 & 140 & blue \\
\hline Fructose & & & & & 0.25 & 125 & 0.51 & 113 & brown \\
\hline Glucose & 0.53 & 100 & 0.69 & 100 & 0.20 & 100 & 0.45 & 100 & purple=blue \\
\hline Galactose & 0.43 & 81 & 0.62 & 90 & 0.16 & 80 & 0.39 & 87 & blue . \\
\hline Sucrose & - & - & - & - & 0.11 & 55 & 0.32 & 71 & brown \\
\hline Maltose & 0.24 & 45 & 0.43 & 62 & 0.08 & 40 & 0.24 & 53 & blue \\
\hline Lactose & 0.16 & 30 & 0.29 & 42 & 0.05 & 25 & 0.17 & 38 & blue \\
\hline
\end{tabular}

* $\mathrm{R}_{\mathrm{x}}=\frac{\text { migration distance of the assay }}{\text { migration distance of glucose }} \times 100 ;$ glucose has been selected as a reference

** Values obtained after one development $(10 \mathrm{~min}$ ) in solvent I (ethyl acetate/isopropanol/water (volumes, $66+30+6)$ ) and detection of sugar dansylhydrazone fluorescent spots at $350 \mathrm{~nm}$

*** Values obtained after a second development $(10 \mathrm{~min})$ in solvent II (ethyl acetate/isopropanol/water (volumes, 60+30+1.2)) and naphthoresorcinol staining of non-dansylated sugars. 


\section{Results and Discussion}

Comparison of radial and linear thin layer chromatography in solvents I and II (tab. 1, figs. 1, 2, 3, 4) shows that resolution is better using the radial meth- od. For dansylhydrazones, radial thin layer chromatography appears to be more suitable than linear thin layer chromatography. The dansylhydrazones of lactose, maltose, galactose, glucose, xylose and ribose can be observed in order of increasing mobility.
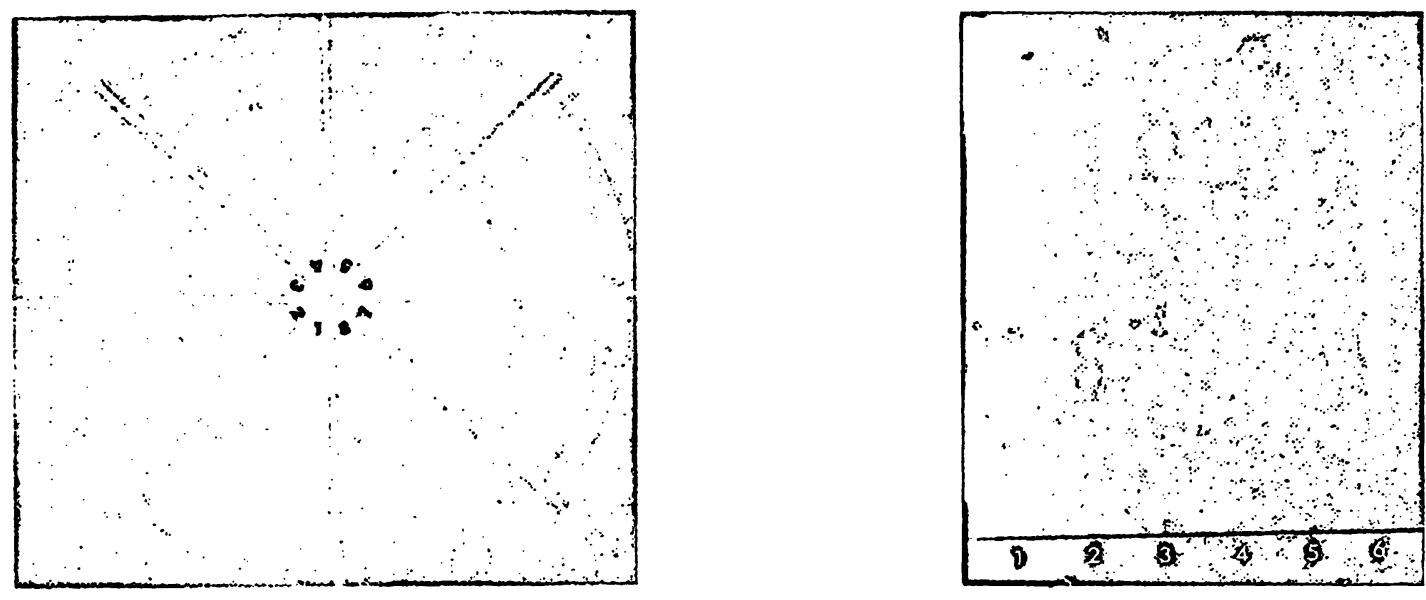

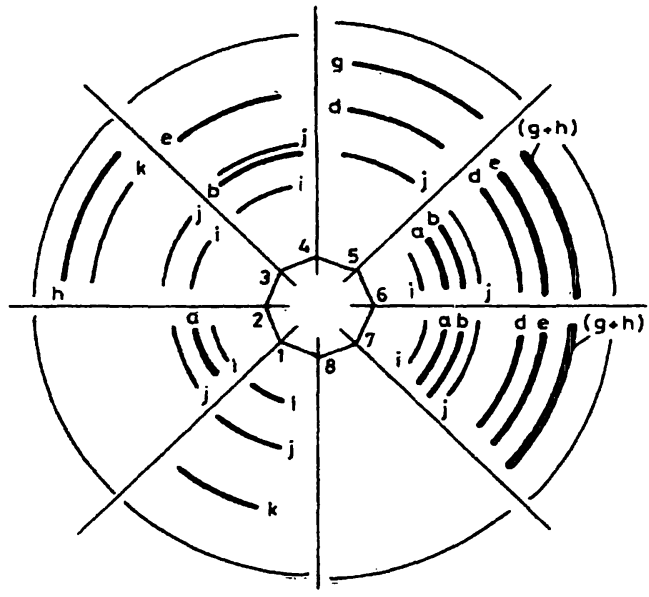

Figure la
Figure $1 b$

Spotting: 1 - Urine without sugars, treated with dansylhydrazine: $0.5 \mu \mathrm{l}$

2 - Dansylhydrazones of fructose $(0.25 \mu \mathrm{g})+$ lactose $(0.5 \mu \mathrm{g})$

3 - Dansylhydrazones of sucrose $(0.5 \mu \mathrm{g})+$ ribose $(0.25 \mu \mathrm{g})$

4 - Dansylhydrazones of glucose $(0.25 \mu \mathrm{g})+$ maltose $(0.5 \mu \mathrm{g})$

5 - Dansylhydrazones of galactose $(0.25 \mu \mathrm{g})+$ xylose $(0.25 \mu \mathrm{g})$

6 - Mixture of the dansylhydrazones of eight standard sugars, $0.25 \mu \mathrm{g}$ and $0.50 \mu \mathrm{g}$ for each mono- and disaccharide, respectively.

7 - The same mixture as in 6 , with $0.125 \mu \mathrm{g}$ and $0.25 \mu \mathrm{g}$ for each mono- and disaccharide.

8 - Untreated sucrose $(1.25 \mu \mathrm{g})+$ untreated fructose $(1.25 \mu \mathrm{g})$.
a: Dansylhydrazones of lactose
b: Dansylhydrazones of maltose
d: Dansylhydrazones of galactose
e: Dansylhydrazones of glucose
$\mathrm{g}$ : Dansylhydrazones of xylose
h: Dansylhydrazones of ribose
$i, j, k$ : by-products of dansylhydrazine

Fig. 1. Comparative study of the resolution of sugar dansylhydrazones by circular (a) and linear (b) chromatography after one development in eluent 1 . Detection of the dansylhydrazones at $350 \mathrm{~nm}$. 
The three fluorescent spots in sector 1 (fig. 1) are byproducts of dansylhydrazine. Dansylsulphonic acid appears as a blue fluorescent spot; the excess of dansylhydrazine yields a yellow fluorescence, which runs with the solvent front and does not interfere with the dansylhydrazones.

The lower detection limit for glucose was found to be in the range of 1 to $2 \mathrm{nmol}(3)$.

The weak fluorescence observed with fructose is probably due to the lower reactivity of ketoses with dansylhydrazine.

Sucrose is not dansylated, because of its non-reducing character. However, the trichloroacetic acid ne- cessary for the dansylation reaction induces partial hydrolysis, releasing some glucose; this is turned into dansylhydrazone, thereby falsẹly indicating glucose in the original sample (spot 3, fig. 1). This type of error çan be monitored by also spotting pure sucrose and an aliquot of non dansylated sample; only one spot of sucrose is then observed. Figure 2 shows, for both radial and linear techniques, the resolution of non dansylated sugars after two successive developments; detection was with the naphthoresorcinol reagent. The dansylated sugars do not interfere with the free sugars since they run with the solvent front and are poorly stained with naphthoresorcinol reagent. In increasing order, the mobilities of the free sugars are lactóse, maltose, sucrose, galactose, glu-
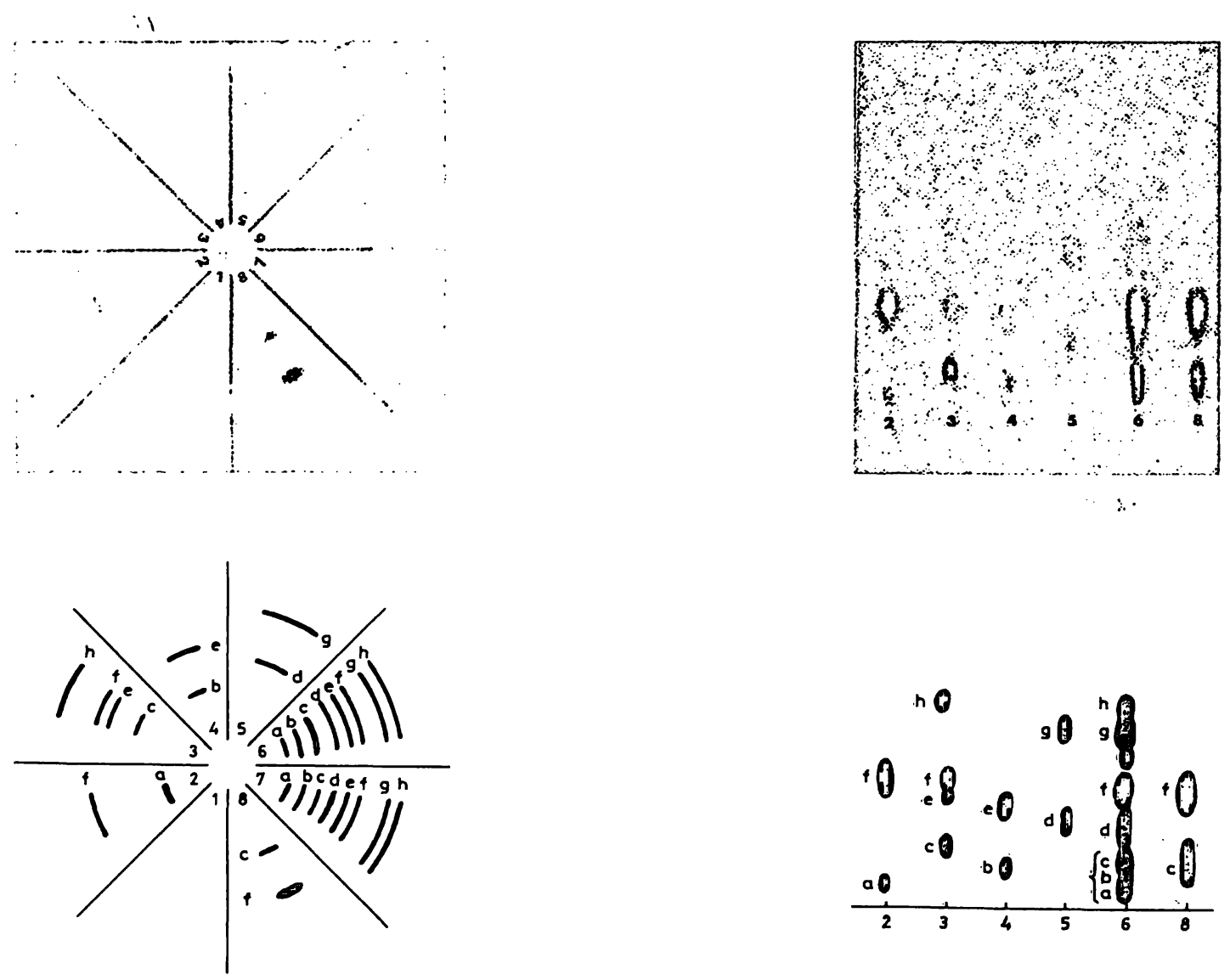

Figure 2a
a: lactose
b: maltose
c: sucrose
d: galactose
e: glucose
$f$ : fructose
g: xylose
h: ribose

Figure 2b

Fig. 2. Comparative study of the resolution of untreated sugars by circulàr (a) and linear (b) chromatography following two successive developments in eluent I and II. Staining with the naphthoresorcinol reagent. Spotting: as in figure 1 
cose, fructose, xylose and ribose. The radial thin layer chromatography still improves the resolution (fig. 3). Furthermore, ketoses and aldoses give different colours, providing one more criterion of differentiation.

All these considerations make it apparent that the proposed method has greater resolution, and is time saving and more specific. Consequently, it can be used with advantage in the diagnosis of various metabolic diseases such as pentosuria, essential fructosu- ria, galactosaemia and intestinal disaccharidase deficiency. In addition to the analytical interest of the fluorescent label, we think that the circular development technique offers many possibilities for the analysis of mono- and oligosaccharides in various biological fluids. We would like to point out the important study made by Mac Laren \& Won (5) concerning the separation of urine oligosaccharides by radial diffusion for the screening of congenital oligosaccharidoses.

\section{References}

1. Gauch, R., Leuenberger, U. \& Baumgartner, E. (1979) J. Chromatogr. 174, 195-200.

2. Mac Laren, J. \& Ng Won, G. (1979) Clin. Chem. 25, 1289-1292.

3. Avigad, G. (1977) J. Chromatogr. 139, 343-347.

4. Biou, D. \& Pays, M. (1979) Toxicol. Europ. Res. 1, 7-23.

5. Prey, V., Berlalk, H. \& Kausz, M. (1961) Mikrochimica Acta 968-97.
Pr M. Pays

Department of Clinical Biochemistry

Centre Hospitalier A. Mignot

177 , rue de Versailles

F-78150 Le Chesnay 
。 . 